\title{
> Seleção de microcontos de Mario Halley Mora traduzidos ao português
}

> Selection of Mario Halley Mora microfictions translated into Portuguese

\section{tradução de Luiz Roberto Lins Almeida}

Licenciado em Letras Português pela Universidade Federal de Santa Maria, Bacharel em Direito pela Universidade Federal de Mato Grosso do Sul. Email:luizrlins@hotmail.com. ORCID: 0000-0002-7267-9601.

\section{tradução de Maria Liz Benitez Almeida}

Doutoranda em Letras na Universidade Federal do Rio Grande do Sul, Mestre em Comunicação pela Universidade Federal de Santa Maria, Mestre em Comunicación para el desarrollo pela Universidad Nacional del Este. E-mail: lizbet3006@hotmail.com. ORCID: 0000-0002-8397-2045. 


\section{Apresentação}

Pouco conhecido no Brasil, Mario Halley Mora (1926-2003), além de ter sido jornalista e chefe de redação do jornal La Patria, foi um dos mais produtivos escritores paraguaios. Sua obra passeia por diversos gêneros literários: poemas, contos, romances, letras de música, roteiros de cinema, tirinhas de jornal ${ }^{1}$. Em especial, destacou-se como dramaturgo, com mais de 60 peças teatrais, que continuam sendo encenadas ${ }^{2}$. Além disso, sua popularidade em seu país também pode ser percebida pela indicação de seus livros em listas de mais vendidos ${ }^{3}$.

De sua vasta produção literária, destacam-se as obras teatrais un rostro para Ana, Testigo falso, En busca de María; os romances Los hombres de Celina e Amor de Invierno; e as narrativas curtas apresentadas em Cuentos, Microcuentos y Anticuentos.

Seu romance Las raíces de la aurora serviu de base para o roteiro do filme La sangre y la semilla, escrito por Augusto Roa Bastos, expoente da literatura paraguaia. O filme tornou-se marco da cinematografia paraguaia e foi o primeiro, naquele país, a abordar a temática da Guerra da Tríplice Aliança.

Para esta apresentação, selecionamos 37 microcontos constantes da obra Cuentos, Microcuentos y Anticuentos, publicada em 1987 pela editora El Lector ${ }^{4}$. Nessa obra, que introduz os microcontos na literatura paraguaia, Mario Halley Mora faz diversos experimentos narrativos, a começar pela escolha de focos

\footnotetext{
${ }^{1}$ José Vicente P. Barco, Literatura y sociedad. La narrativa paraguaya actual (1980-1995), 2001.

${ }^{2}$ ABC, “El solterón", de Mario Halley Mora, en el Arlequín, 2019.

${ }^{3}$ Última Hora, Novelas, ensayos e historia están entre libros más vendidos del 2016, 2016.

${ }^{4}$ Mario Halley Mora, Cuentos, Microcuentos y Anticuentos, 2003.
} 
narrativos distintos e pela estratégia narrativa, mas também pela própria estrutura de cada um dos textos, assim como pela presença do jopara (fruto do contato linguístico entre o guarani e o espanhol).

Por essa razão, foram selecionados os microcontos nos quais se nota o maior esforço de síntese do autor, que buscou condensar a narrativa ao máximo, construindo-as com apenas um parágrafo. Por essa razão, os microcontos Nicanor, Lo grotesco, El puente, e Los dos diários ficaram excluídos deste trabalho, merecendo tradução que possa analisá-los com enfoque nas características dissonantes das que são apresentadas no presente texto.

\section{Genealogia}

Uma raça mais agressiva de macacos expulsou das árvores outra raça mais pacífica e conformista. A tribo vencida exilou-se do arvoredo e foi instalar-se na plana terra. Porém ali, o pasto era alto e denso, e para verem-se uns aos outros e para observar o perigo, os macacos derrotados tiveram que aprender a andar erguidos sobre duas patas. E foi assim que, sem que se houvessem proposto, os conquistadores das árvores, partindo do parente mais infeliz, inventaram o Homem, que se vingaria conquistando o mundo. 


\section{Fúnebre}

Quando nascia, morreu sua mãe no parto. Foi filho órfão de pai viúvo. Casou-se e enviuvou por sua vez, mas antes de morrer sua esposa lhe deu um filho que resultou ser filho órfão de um pai viúvo que era filho órfão de um pai viúvo. Vivem os três na mesma casa, e quando passo em frente a ela, caminho com solenidade, como se passasse na frente de um panteão.

\section{Começo}

Logo deu-se conta de que era inteligente. Fez da caverna um lar. Fabricou ferramentas, aprendeu a acender e a conservar o fogo e inventou as armas. Sentiu-se orgulhosamente superior a toda criatura vivente sobre a face da Terra, e necessitou uma medida de sua própria importância. Então, criou Deus a sua imagem e semelhança.

\section{Mestiçagem}

O conquistador espanhol tomou para si uma jovem índia e tiveram um filho. Outros conquistadores o imitaram e houve muitos espanhóis com muitas mulheres índias. A mestiçagem perfeita, com o homem de uma estirpe e a mulher de outra. A dama espanhola via passar o índio galhardo, desnudo e elástico, e suspirava. O que é perfeito demais deixa de sê-lo.

\section{Na origem}

O fruto que havia arrancado tinha um saboroso aspecto, porém a casca era dura. Então, na mente elementar surgiu uma ideia: podia golpear o fruto com uma pedra e romper o invólucro. Assim o fez com êxito, e inventou desta maneira a 
primeira ferramenta: o martelo. Contente, foi buscar outro fruto. Achou-o e ao repetir a operação esmagou o dedo. Então, inventou o primeiro palavrão.

\section{Dentro de 20 anos}

O garotinho de aspecto saudável e vigoroso montava uma reluzente bicicleta. Passou pedalando rapidamente perto de um engraxate descalço e magro que inopinadamente arrojou um pau entre os raios das rodas que produziram um execrável ruído de metais amassados. O ciclista se deteve e com raiva se dispôs a castigar o malfeitor. $\mathrm{O}$ engraxate esgrimiu ameaçadoramente seu caixote, como clava e escudo ao mesmo tempo. Um senhor que passava os separou. A briga não começou, mas tampouco terminou. Simplesmente estava postergada.

\section{A diferença}

O cachorro lustroso e bem alimentado contemplou através das grades da mansão o cachorrinho sem nome e com pulgas que passava trotando com suas costelas à flor da pele. O cachorro da mansão era de raça selecionada. O cachorrinho era de todas e de nenhuma. E entre os dois cachorros havia uma grande diferença: as grades.

\section{0 vencedor}

O poderoso Doberman atacou ao raquítico vira-lata e deixou-o machucado e sangrando. Não o matou porque apareceu o dono, colocou-lhe a coleira e a corrente, e levou-o para atá-lo ao poste de sempre. Ali esteve cativo, o Doberman sentia na boca o gosto de sangue, e era amargo. O cachorrinho arrastou-se até o 
arroio, deixou que a água lhe lavasse as feridas, e bebeu. E a água era doce, porque tinha o gosto da liberdade.

\section{A pandorga}

A pandorga ficou muito bonita. Os "pauzinhos" de taquara polidos e retos. A armação redonda e equilibrada. Os pedacinhos de celofane cortados, azuis e vermelhos, perfeitos e minuciosamente colados. As longas "tirinhas" ${ }^{5}$ amarelas rodeavam a pandorga como uma cabeleira rumorosa de vento e loira de sol. E finalmente, os "barbantes" simétricos, milimétricos, matemáticos. Era toda uma pandorga, feita para conquistar todos os céus e as alturas mais azuis. Uma obra de arte voadora que o pai fabricava para a admiração do filho. Saíram à rua cheios de alegria para assistir ao voo inaugural desse novo astro de taquaras e papel de seda. O pai esperou o vento, que soprou, que estirou a pandorga e o pai deu linha permitindo que se elevasse com um rumor de alegria sedosa. Veio outra rajada de vento, e a pandorga a escalou vitoriosa, sacudindo sua melena dourada. Já se fazia pequena na altura, quando de repente sobreveio o fim do mundo. Afrouxouse a força do vento, que ficou calmo e logo soprou em ângulo distinto. A harmonia se rompeu, os barbantes enlouqueceram, a longa cauda se agitava buscando apoio no vento que havia dado as costas, e de repente uma rajada inesperada, impetuosa e selvagem, e a pandorga de cabeça para baixo cai traçando um itinerário de meteoro que cai estrepitosamente, com um rasgo de pauzinhos e seda rotos, nos fios elétricos. E ali fica, irremediavelmente

\footnotetext{
${ }^{5}$ No original, o autor emprega o termo guarani "pirita", palavra onomatopeica que remete ao som produzido pelas franjas da pandorga.

Milibri Ediciones, Milibri pocket castellano-guaraní, guaraní-castellano: grafía tradicional y científica, 2011, p. 649.
} 
prisioneira. O menino olha o pai, pensando que aquele fazedor de estrelas não é tão genial nem tão infalível como acreditava.

\section{0 patinho feio}

O patinho feio, depois de tanto sofrer, olhou-se no espelho das águas e viu-se convertido em um belo cisne. O filho do granjeiro gritava alvoroçado que tinham o mais formoso cisne das redondezas. Orgulhoso, o ex-patinho feio pensou que seus problemas terminavam. Mas não é assim, pois veio o granjeiro, olhou carrancudo, murmurou que os cisnes não se comem, e o tirou a pontapés do lago.

\section{Círculo vicioso}

Ela era rica. Ele era pobre. Apaixonaram-se. O pai dela, oligarca e plutocrata, disse que não. A mãe dele, humilde e ambiciosa, disse que sim. De ambos os lados, opinaram os parentes, aconselharam os amigos, sentenciaram os velhos e tomaram bandeiras os jovens. Por dois anos, permaneceram firmes em seu amor, e as coisas aconteceram. O pai dela perdeu sua fortuna e mãe dele ganhou a loteria. Eles continuam se amando, mas a mãe dele diz que não, e pai dela, que sim, e os parentes opinam e amigos aconselham, os velhos sentenciam e os jovens tomam bandeiras.

\section{O Círculo}

Quando tinha seis anos foi preso, denunciado por furtar balinhas. Ao longo de sua vida voltou a ser preso por diversas razões. Fez serenatas sem autorização, conspirou, cometeu um ou outro estelionato, bateu em sua mulher e brigou com o vizinho. Também esteve preso por "escândalo em via pública" e por insultar a 
autoridade. A última vez que foi preso já era um idoso de 85 anos, denunciado por furtar balinhas.

\section{Policial}

A filha do ladrão apaixonou-se pelo policial, e foi correspondida. Mas o policial teve que prender o ladrão. Então a filha foi a suplicar a seu amado pela liberdade de seu pai, mas o policial tinha em seu escritório um cartazinho que dizia: “O Dever Diante de Tudo". Ao final, tudo saiu bem, porque como era seu dever deixou preso o ladrão, e como era seu dever casou-se com a filha para não a deixar desamparada.

\section{Segredo}

Tinha 18 anos e os exibia como se fossem quilates. Vestia-se com elegância e distinção, sempre na última moda e o mais caro, apesar de não ser rica. Suas amigas perguntavam-lhe seu método, porém ela calava, porque simplesmente havia descoberto que, para vestir bem, o segredo era desvestir-se bem.

\section{O filho}

Pecaram. Veio um filho que ela quis e ele não. "É um problema seu", lhe disse e desapareceu. O garoto cresceu, e ao aprender a falar aprendeu a perguntar: “Onde está meu papai?". Ela respondia que havia ido a uma longa viagem, e ao dizê-lo, perguntava-se a si mesma a que distância fica o desprezo. 


\section{Mulher}

Ele amava seu gato e ela adorava seu canário. Um dia, o gato comeu o canário e ela ficou inconsolável. Ele foi à venda de animais e lhe trouxe um novo canário, mais bonito e mais cantor que o anterior. Ela devolveu à venda de animais o canário e o trocou por um cachorro.

\section{Tragédia}

Sua esposa foi às compras com o carro e teve um acidente, do qual foi informado telefonicamente por um amigo. Ao escutar a notícia sentiu um desfalecimento de pânico, uma sensação de perda, uma predestinação de tragédia irreparável, e com voz trêmula, perguntou ao amigo: “Que aconteceu com o carro?”...

\section{0 jardineiro}

Ele tinha 55 anos e ela 20. Ela quis desenhar um novo jardim e o esposo consentiu. Dividiram o trabalho, e enquanto ele comprava as sementes, ela contratou o jardineiro. As rosas florescem e resplandecem. E ela, mais.

\section{Defesa}

A viúva jovem e a divorciada linda iam sempre juntas, mas não eram amigas, senão aliadas, como soldados da infantaria que se colocam costas contra costas para combater melhor. 


\section{Sexo e H.P.}

Ele dirigia um barulhento $2 \mathrm{CV}$. Ela o ultrapassou como uma centelha ao volante do Alfa Romeo Super Sport. Ele não teve outro remédio senão sentir-se menos masculino, mas se consolou no pouco feminina que era a garota ao volante daquela besta mecânica. E ao final, deduziu filosoficamente que a igualdade de sexos também pode ser uma questão de HP.

\section{Amor e Ciúmes}

Foi o primeiro amor, e como sempre acontece, ela casou-se com outro, ele permaneceu solteiro, um pouco por desilusão e outro pouco por comodidade. Ela teve uma filha que era seu retrato vivo. Ele, já maduro, conheceu a filha de seu antigo amor, e amou-a como havia amado sua mãe, e a moça amou ao galã maduro como não o tinha amado sua mãe. A mãe sente ciúmes ardentes, mas ainda não está certa de quem.

\section{Loucuras}

A louca me olhou através das grades e sorriu. Era jovem e bonita e sonhei com fazer minha aquela mulher depois de resgatá-la da obscuridade. Voltei uma e outra vez, porém o médico me disse: "É incurável". Olhava-a e doíam-me sua beleza e seu sorriso de menina crédula. Meu sonho de curá-la e de tê-la fez-se cinzas, pois ela nunca seria lúcida. Entretanto, agora somos felizes. Eu me tornei louco, estamos juntos. 


\section{Viver?}

Carlos morreu aos 76 anos. Aos 20, havia começado a trabalhar como empregado em um grande armazém, e se aposentou aos 50. Ainda jovem, voltou empregarse em outro armazém, e se aposentou aos 75, morrendo um ano depois, quase sem fruir de sua dupla aposentadoria. De sua parte, Raul morreu aos 32 anos. Aos 15, fugiu de seu lar e viajou como ajudante de cozinheiro em um barco de alémmar. Foi garçom em Paris, músico em Atenas, soldado na África, crupiê em Monte Carlo e gondoleiro em Veneza. Quando tinha 32 anos, um marinheiro ciumento matou-o. Carlos viveu muito, porém viveu pouco. Raul viveu pouco, porém viveu muito.

\section{Ministro}

Passava o tempo murmurando: "Se eu fosse ministro". E um bom dia o foi. Avolumaram-se os problemas de tal forma, que se esqueceu das fórmulas milagrosas em que pensava quando queria ser ministro. Então, saiu à rua e, encarando um cidadão com ar de infeliz, perguntou-lhe: "Que você faria se fosse ministro?"

\section{0 anos}

Quando fez 50 anos, decidiu comemorá-los com os amigos de quando tinha 25. Eduardo, o dançarino incansável; Federico, o sedutor; Arsênio, o infatigável contador de piadas; Juan Carlos, o prodigioso bebedor de cerveja. A ideia era recordar tempos felizes, e vieram todos, porém as lembranças foram ficando aos pedaços no itinerário dos anos. Além do mais, o dançarino tinha reumatismo, e o sedutor olhava seu relógio com angústia, desejoso de voltar para casa, e o 
contador de piadas as havia esquecido todas, enterrada sua alegria sob os escombros de uma aposentadoria miserável, e o bebedor de cerveja só tomava coca-cola, por causa seu fígado. Quando se foram todos, disse a si mesmo desconsolado: "Os 50 anos não se celebram. Desabam sobre nós".

\section{Diferença}

O velhinho estava sentado em um banco da praça. A velhinha em outro. Passou uma jovenzinha e o velhinho olhou-a com luxúria. Passou um jovenzinho e a velhinha olhou-o com ternura. O velhinho sonhava voltar a ser jovem, para Viver. A velhinha estava contente em seguir sendo avó, antes de Morrer.

\section{Castigo}

Quando era criança, caçava passarinhos com um rifle de ar comprimido. A carne quase imaterial dos canários e dos pardais destroçava-se ao impacto de suas munições. Plumas azuis, verdes, amarelas, vermelhas manchavam-se com a púrpura do sangue. Cresceu, fez-se homem e já não matava passarinhos, mas sim javalis assustados, antas bonachonas, tigres acossados, veados que ainda na morte tinham em seus olhos o pânico e a angústia. Envelheceu e morreu. No inferno inventaram um castigo novo para ele: passear por um bosque encantado, iluminado de gorjeios e cheio de caça. E ele desarmado.

\section{História}

Quando ele era criança, sua mãe ficou viúva e casou-se de novo. Seu padrasto queria ter uma família sua, e enviaram-no para viver com uma tia. Apertou os lábios e não se queixou. Fez-se homem e castigou sua mãe em todas as mulheres. 
Não amou a nenhuma e a todas usou. Quando precisava de companhia feminina, pagava. Pagava suas amantes, suas enfermeiras, suas companheiras de excursão, a que cuidava da roupa e a que limpava seu apartamento. Morreu velho e sozinho e, na solidão do grande quarto de dormir, quando sentia que se fundia naquele nada sem nome, estendeu as mãos e sussurrou o chamado terno e desesperado que postergou desde sempre: Mamãe!

\section{Frustração}

Sua mania eram os velórios. Gostava do mórbido prazer de dar as condolências. Invejava a dor dos parentes e até a triste majestade do cadáver jacente entre madeiras lustrosas e rasas. Vivia sonhando com seu próprio velório como o pobre sonha com sua casinha própria, e passava horas de insônia imaginando seu ataúde, a montanha de coroas e as frases patéticas estampadas em um álbum à luz dos círios. Tanto esperou que enfim se cumpriu o sonho da sua vida: morrer. Porém o único velório a que não pôde assistir foi o seu, porque morreu afogado e o rio levou-o.

\section{A vida continua}

Já estava enterrado há oito dias. No nono, sua viúva decidiu abrir as janelas da casa e entrou o sol com o brilho quase irreverente. De tarde ela olhou-se ao espelho, viu-se pálida e permitiu-se um toquezinho de maquiagem. Um pouco depois, sua filha voltou do colégio, pôs um disco no aparelho de som e a música tirou, como que por empurrões, a tristeza que havia estado fermentando na obscuridade da casa fechada. Mais tarde, tocou o telefone e o filho atendeu a chamada de uma menina, e houve risos. O esquecimento havia começado. 


\section{Sucesso}

Imensa pena causou em diversos círculos a morte daquele cidadão excepcional. O comércio, indústria, o esporte e a cultura dedicaram-lhe bandeiras enlutadas. Os jornais dedicaram-lhe compungidos artigos necrológicos, e um deles expressou que a Pátria inclinava a cabeça, entristecida pela perda. No entanto, pouquíssima gente foi ao enterro. Choveu.

\section{Encontro}

Voltei a ver meu primeiro amor. Presenteou-me a sombra de um sorriso e foi de braço dado com seu esposo. Devolvi-lhe seu esboço de sorriso e me fui de braço dado com minha esposa. Mas os dois sorrisos ficaram ali, deram-se as mãos e foram caminhando pelas ruas da nostalgia.

\section{Extremos}

O neto e o avô, sentados na grama verde, viam passar o trem, como de brinquedo, lá no fundo do vale. O avô, que vinha de muitas partes e estava chegando ao destino, perguntava-se: “De onde virá?" O neto, que ainda tinha que andar todos os caminhos, perguntava-se: “Aonde irá?".

\section{Homem Feliz}

Voltaram os mensageiros e informaram ao rei que o homem feliz não tinha camisa. Então o rei assinou um decreto proibindo a todos os homens do Reino que usassem camisa. No entanto, em lugar de epidemia de felicidade, houve outra de pneumonia. Furioso, o rei mandou enforcar aos mensageiros mentirosos. 


\section{$O$ fim do mundo}

Todos os observatórios astronômicos do mundo, os cientistas e os computadores confirmaram que o fim do mundo ocorreria dentro de cem anos. Cada habitante do planeta suspirou de alívio porque não veria o cataclismo. E, na verdade, esse dia, cem anos antes, começara o fim do mundo.

\section{O rio}

Quando ia rio acima, do barco divisei o ranchinho que aparecia na margem. Uma mulher lavava roupa, dois garotinhos brincavam na prainha e um homem pescava a comida do dia. Tempos depois, voltando rio abaixo, vi que as águas haviam aumentado e do ranchinho apenas se via um teto de palha. Os quatro haviam partido para começar de novo, então pensei que o rio é como a vida: nos alimenta pouco a pouco, e nos come de uma só vez.

\section{9 anos}

Quando fiz quarenta e nove anos, olhei um álbum e encontrei um retrato de meu pai, que morreu aos 42. Absurdo e real, ali estava meu pai, mais jovem que eu, destruindo uma relação que acreditava eterna. Então, dei-me conta de que acabava de receber meu diploma de velho.

\section{Referências}

ABC. "El solterón", de Mario Halley Mora, en el Arlequín, 2019. Disponivel em: https://www.abc.com.py/espectaculos/cultura/2019/12/10/el-solteron-demario-halley-mora-en-el-arlequin/. Acesso em: 04 jan. 2020. 
BARCO, José Vicente P. Literatura y sociedad. La narrativa paraguaya actual (1980-1995). Tese (Doutorado em Filologia) - Faculdad de Filología, Universidad Nacional de Educación a Distancia, Madrid, Espanha, 2001.

MÉNDEZ-FAITH, Teresa. Breve diccionario de la literatura paraguaya. Biblioteca Virtual Miguel de Cervantes, Alicante, 2001. Disponivel em: http://www.cervantesvirtual.com/obra/breve-diccionario-de-la-literaturaparaguaya--0/. Acesso em: 04 jan. 2020.

MILIBRI EDICIONES. Milibri pocket castellano-guaraní, guaraní-castellano: grafía tradicional y científica. Asunción: Milibri Ediciones SRL., 2011. 702 p.

MORA, Mario Halley. Cuentos, Microcuentos y Anticuentos. Asunción: EI Lector, 2003.

ÚLTIMA HORA. Novelas, ensayos e historia están entre libros más vendidos del 2016. 2016. Disponivel em: https://www.ultimahora.com/novelas-ensayos-ehistoria-estan-libros-mas-vendidos-del-2016-n993326.html. Acesso em: 04 jan. 2020.

\section{Referência para citação desta tradução}

ALMEIDA, Luiz Roberto Lins; ALMEIDA, Maria Liz Benitez. Seleção de microcontos de Mario Halley Mora traduzidos ao português. Revista PHILIA | Filosofia, Literatura \& Arte, Porto Alegre, volume 2, número 1, p. 629 644 , junho de 2020. 